\title{
Mare Kõiva
}

\section{MIGRATSIOON JA LÄÄNEDIASPORAA PÄRIMUS}

Läbi 20. sajandi on eesti (lääne)diasporaa olnud rahvusliku identiteedi säilitaja ja kodu-Eesti toetaja. Nõukogude annektsiooni ajal arendasid kogukonnad hajalas eesti majade ja seltside vahendusel omariiklust, esindades Eestit poliitiliselt ja kultuuriliselt, tuletades meelde ta olemasolu. Läänediasporaa väikesed alternatiivsed omavahel seotud Eestid tuginesid sageli varasematele kohalikele, paiguti juba 19. sajandil väljarännanute kogukondadele, kellega koos rajati rikas seltsi-, kultuuri- ja spordielu, algatati suveülikoole, teadusseltse, kirjastamissüsteeme. Uuel kodumaal rajatud spordikompleksid ja puhkekodud on tänini kasutusel, ehkki asutatud koolid ja edendatud kursused on asurkonna vananedes ja järeltulijate keeleoskuse taandudes kahanenud.

Pärast Teist maailmasõda toimus kogu seesugune sundpagulaste elu ülesehitamise kõrval, ja nagu varemgi, vabal ajal ja vabatahtliku tööga. Haruldane polnud, et omakultuuri arendamine ja keele säilitamine oli vastuolus uue asukohamaa ametliku rahvuspoliitikaga, sest leebemad migratsiooniseadused ja paljurahvuslikkuse väärtustamine riigi rikkuse alusena on uuemad trendid (vt nt Collins 1991; Vertovec 1999; Rooth 1999).

Institutsionaalset eesti elu kajastavad trükised, sh ülevaateteosed ja aastaraamatud, isiklikku paradigmat edastavad kirjad, päevikud, ilukirjandus ja elulood. Trükised dokumenteerivad eestluse käekäi$\mathrm{ku}$, isiksusekeskne lähenemine algas hiljem ning vajab veel hoolikat kogumistööd ja analüüsimist. 
Projektid

Iga säärane kogukond on mingis mõttes olnud miniatuurne Eesti oma poliitilise keskme, juhtkonna ja laiahaardelise tegevusega. Läänediasporaa kogukonnad on suhelnud omavahel eesti päevade ja suveülikoolide vahendusel, poliitiliste olude leebudes 1950. aastate teisel poolel taastus suhtlemine sugulaste ja ametikaaslastega kodumaal. Poliitilise toetuse kõrval on hindamatu just diasporaa humaanne toetus sugulastele, koolikaaslastele ja sõpradele: pakid, kirjad, telefonikõned, külaskäigud. Tahtmata kuidagi alahinnata materiaalset abi rasketel sõjajärgsetel ja kolhoosistamise aegadel arvan, et moraalne tugi ning teadmine vabadest ja edukatest kaasmaalastest välismaal oli ainelisest toetusest hinnalisem.

Suuremad diasporaa kogukonnad on oma seltsielu dokumenteerinud. Näiteks Austraalia diasporaa seltsielu kajastavad kohalikud perioodilised väljaanded ja raadio, samuti väiketrükised. Melbourne'i arhiivi kroonikates leiduvad iga sündmuse ja kogunemise kohta fotod, protokollid ja ürituste kavad. Kommenteeritud fotoalbum jäädvustab ka käsitööringi tegemisi. Tava koostada juubeliks spetsiaalne fotodega seinaleht on laiemalt levinud erinevates kogukondades.

Läänediasporaa huvi suulise ajaloo ja biograafiate vastu on umbes sama vana või veidi hilisem kui kodumaal alanud suured ajaloolise pärimuse, suulise ajaloo ja elulugude kogumise aktsioonid, mis ulatuvad muinsuskaitseliikumise aegadesse ehk napilt taasiseseisvuse-eelsesse aega. Siiski tuleb mainida, et paljud paadipõgenikud ja pagulased hajalas on ise dokumenteerinud oma eluloo, eriti põgenemise ja asukohamaal kohanemise loo, pannes selle kirja oma laste jaoks. Seesugused illustreeritud elulood võivad järgida päeviku ülesehitust ja tuginedagi kirjutaja päevikule. Mõistagi ei ole see ainuke vormivõte. Käsikirju on paljundatud mõnest koopiast kümnekonna eksemplarini. Nende sihiks on jäädvustada järeltulijaile oma põlvkonna ja iseenda saatus keerukatel aegadel. Niisugused mälestusraamatud, arvestades eriti lapselaste raskusi eesti keelega, võivad olla kirjutatud asuko- 
hamaa keeles. Austraalia elulugude jäädvustamise projekt Sidney Eesti arhiivi juures videosalvestas 1990. aastatel valitud, valdavalt ingliskeelseid elulugusid (Simmul 2001; Kõiva 2002).

Läänediasporaa intervjueerimine ning nende folkloori kogumine annab võimaluse jälgida, kuidas rekonstrueeriti välismaal kodumaad, adapteeruti erinevates oludes ja uutes kultuurilistes keskkondades ning millised olid harjumuspäraste etniliste kultuurimudelite säilitamise viisid. Eesti ja diasporaa omavahelised mõjud on seni vähe folkloristide tähelepanu pälvinud.

\section{Kogumistöö}

1996. aastal liitus Mare Kõiva (Lars Fiärta stipendiumi toel) Aino Laaguse algatatud projektiga Lõunarootsi eestlaste keel ja kultuur. Kuu aega kestnud stipendiumi sihiks oli jätkata projekti heaks Rootsi ühe huvitavama kogukonna intervjueerimist. Kunagise kirjastamise, tugeva teadus- ja rahvusliku keskuse elu oli osa vaimsete liidrite surma ja teiste vananemise tõttu muutumas. Siiski oli see sedavõrd mitmekesine kooslus, et üksnes lindistamine tundus ohtliku raiskamisena. Visuaalselt jäädvustas viimase nädala jooksul Lundi-Malmö ja lähikonna pärimust Eesti Teadusfondi toetusel Andres Kuperjanov. Hilisemaid lühikesi täpsustavaid intervjueerimisi on toetanud Eesti Teaduste Akadeemia välisvahetuse programm. Lähtudes samast temaatikast intervjueeris Mare Kõiva AAASi (American Association for the Advancement of Science, eesti k Ameerika Teaduse Arendamise Assotsiatsioon) kongressi ajal ja järel USAs Seattle'i eestlasi 1997. aastal ning taas koos Andres Kuperjanoviga 2001. aastal Austraalias. Sealne ainestik on lindistatud, filmitud ja fotografeeritud 13. juulist 3. augustini, seega Rahvusvahelise Rahvajutu-uurijate Seltsi (ISFNR) 13. maailmakongressi eel, ajal ja järel. Melbourne' ist liiguti backpacker-reisiga Canberra kaudu Sidneysse, kus küsitlemine jätkus. Kaks päeva oli tänu perekond Salasoole võimalik lindistada Thirlmere eesti külas. 
Projektid

Küsitlused toimusid enamasti avatud intervjuuna. Lähtudes ülesandest jäädvustada keelekasutust, orienteerusime eestikeelsetele intervjuudele, mis määras informantide valiku. Rootsi intervjuudest tehti suurem osa Lundi Ülikooli soome-ugri instituudi raamatukogus, kuhu kohalikud saabusid telefonitsi kokkulepitud intervjuudeks, vanemaid inimesi külastati nende kodudes, ka korduvintervjuud tehti reeglina koduses miljöös. Lindistati ja filmiti perekondlikke koosviibimisi, kogunemisi kohalikus Eesti Majas ja kohvikus, jäädvustati Lundi eesti pühapäevakooli tundi, Tartu Ülikooli aastapäeva ja jõulupidu, ühe rahvuslase matuseid jm. Hilisemate intervjuudega püüti tihendada eelnevat valikut ehk siis intervjueerida keskmise põlvkonna seltsielu-, meedia- ja äritegelasi Lundis, Malmös ja nende ümbruskonnas, samuti teha korduvintervjuusid rikka pärimusega informantide juures.

Palju abi oli eesti keele lektori ametit pidava Aino Laaguse näpunäiteist ja Lundi korteriperemehest Jaak Tammertist. 1934. aastal sündinud Tammerti kodune "muusika- ja filmiakadeemia" aitas sisse elada lastena Rootsi saabunute põlvkonna eestluse kujunemisele ja nende valikutele. Et Tammert oli parajasti töötu, luges ta päevaste intervjuude ajal folklooriraamatuid ja kaasavõetud käsikirju ning põimis oma õhtustesse spontaansetesse meenutustesse analoogilisi palu manalateele läinud sugulaste ja eestlaskonna liikmete repertuaarist. Malmös intervjueerimisel abistasid Lydia Becker-Koern ja tema rootsi sõber Gustav.

Kui Lundi ja Malmö asurkonnani jõudis jala ja linnatranspordiga, siis Ameerikas ja Austraalia miljonilinnades olnuks lahke abita võimatu intervjueerida. Ameerikas abistas perekond Raja, kelle kodus valmis Seattle'i eestlaste kohalik ajaleht, Austraalias aga Glory Toom ja perekond Salasoo. Austraalia puhul rakendati isikuintervjuude kõrval taas võimalust lindistada erinevate seltskondade koosviibimisi, tööd eesti ajalehe toimetuses, eestikeelse raadiosaate valmimist, abi- 


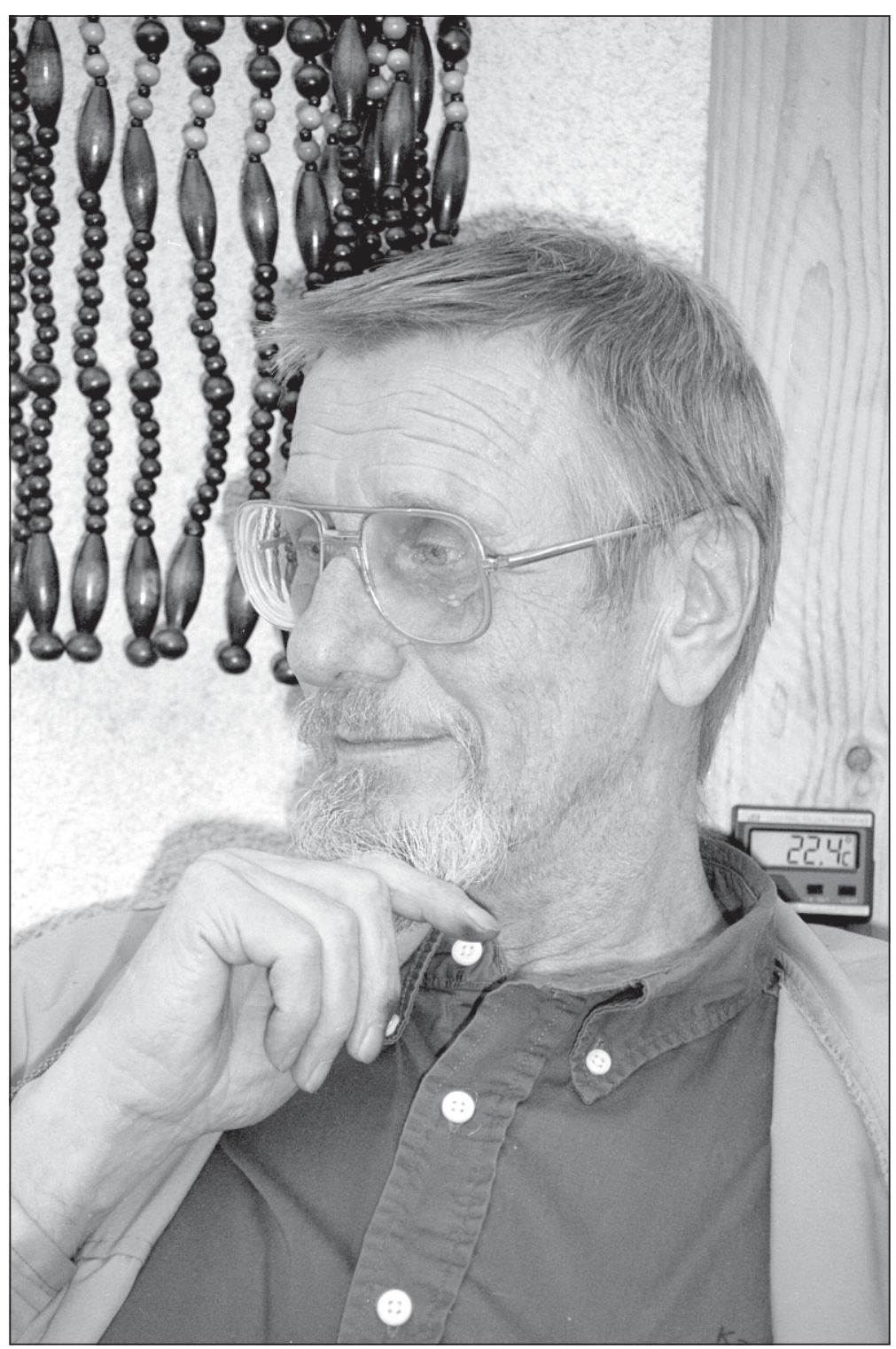

Foto 1. Suurepärane jutustaja Jaak Tammert Lundist esindab Rootsis kasvanud ja hariduse saanud eestlasi. Andres Kuperjanov foto 1997. 
Projektid

töid Sidney arhiivi korraldamisel jm. Seesugused segaintervjuud jäid küll kvaliteedilt nigelamateks, kuid andsid parema ülevaate keele kasutamisest erinevates situatsioonides.

Visuaalse materjali salvestamisel kasutasime 1970. aastatel ja varem tavakohast võtet, et lindistamisega paralleelselt ka filmiti või pildistati, saamaks spontaansemaid kaadreid. Kodumiljööd jäädvustati ka enne ja pärast lindistamist.

Ajaline piiratus ja tohutud vahemaad sundisid orienteeruma eelnevatele kokkulepetele ja kohtadele, kus oli võimalik intervjueerida mitut inimest järjest või elas lähestikku mitu eestlast. Kodude kõrval küsitlesime Eesti Majades. Ajapiirangu tõttu on suurem osa Austraalia küsitlustest lühiintervjuud, mis kestsid poolteisest kahe tunnini. Üksnes mõningaid inimesi õnnestus korduvalt intervjueerida, mitmed huvitavad kohtumised hilismigrantidega jäid päevikumärkmetesse.

Kokku on rootsieestlastelt talletatud 57 tundi ainestikku, Seattle'i eestlastelt 4 tundi ja austraaliaeestlastelt 31 tundi ainestikku. Audiovisuaalsete salvestuste kõrval on tehtud sadu fotosid ja vähemal määral üleskirjutusi. Austraaliast varem kaasa toodud või intervjueerimismatka ajal kohalike poolt kirja pandud elulood ning muud kirjapanekud on antud hoiule Eesti Kultuuriloolisesse Arhiivi, esemed on antud üle Eesti Rahva Muuseumi.

\section{Uurimissihid}

Liitumine projektiga Lõuna-Rootsi eestlaste keel ja kultuur tõi eeltingimusena kaasa orienteerumise suulise ajaloo ja põgenemislugude jäädvustamisele. Suurem osa intervjueeritutest olid poliitilised või erinevatel põhjustel kodumaalt lahkunud sõjapõgenikud, enamiku lähemad sugulased olid küüditatud 1941. aasta juunis Venemaale. Peaaegu kõikjal oli olemas varasem, eeskätt majandusmigratsiooni ajel saabunute kogukond, kellega koos hakkasid Teise maailmasõja 


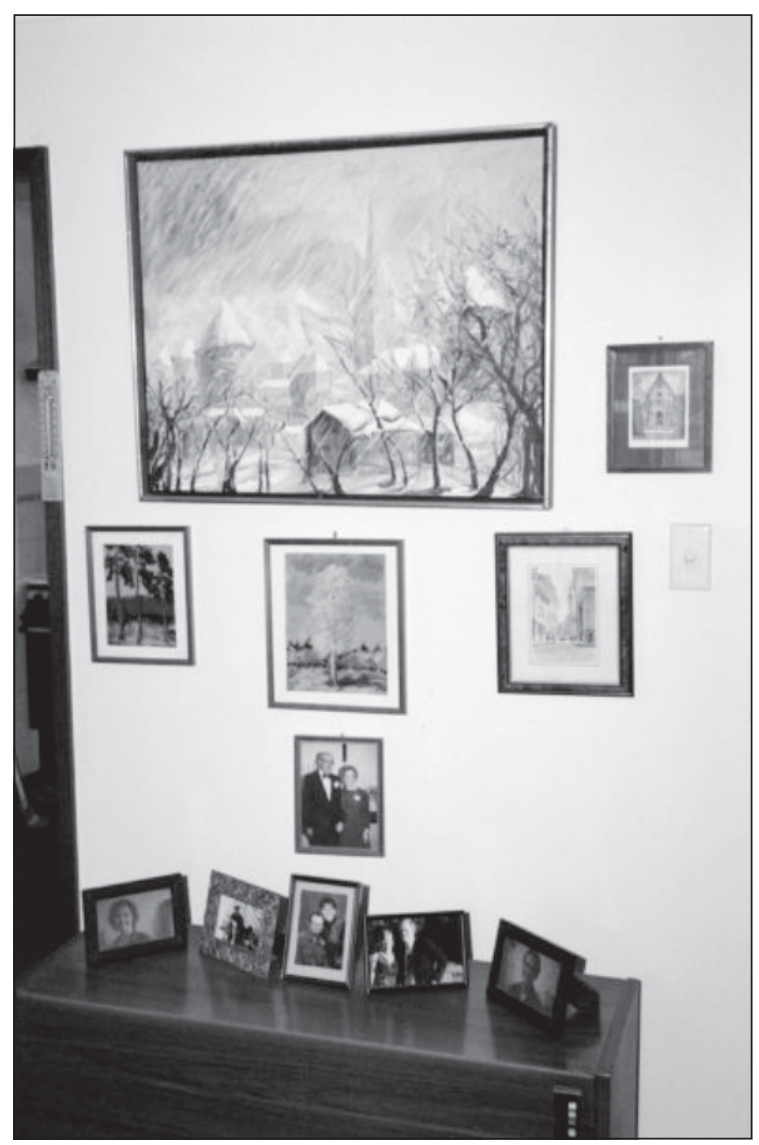

Foto 2. Austraaliaeestlaste maalidelt ja käsitöödelt vaatavad vastu tuttavad eesti motiivid. Andres Kuperjanovi foto 2001 .

aegsed ja järgsed pagulased arendama eesti elu. Alates 1960. aastatest oli taas ka Eestist välismaale sugulaste juurde kolitud, eeskätt pääses sinna väljarännanute vanemaid. Mõnevõrra laienes diasporaa ka kodueestlastega abiellumise kaudu. Viimaste kümnendite jooksul ongi erinevas vanuses sisserännanute hulgas märgatav pereloomise tõttu saabunute hulk. Kindla kontingendi moodustavad sh pensionärid, kes on toonud endale Eestist rahvuskaaslasest elukaaslase - 
Projektid

mõnikord teise eaka inimese. Noored on välismaal töötades või reisides leidnud mitte-eestlasest elukaaslase. Osa sel viisil saabunuist on loonud sideme rahvuskaaslastega. Sarnaselt 19. ja 20. sajandi algusega on kasvanud majandus- ja turismimigrantide osa, kellele on sobinud vastav keskkond või sotsiaalsed garantiid.

Suulise ajaloo ja põgenemislugude kõrval oli intervjuude sihiks jäädvustada adapteerumist uues keele- ja kultuurikeskkonnas, harjumuspäratutes looduslikes oludes. Kuivõrd kõigis kogukondades oli ühiselu keskmeks Eesti Maja, siis huvitas, milliste vahenditega konstrueeriti eesti immigrantide ühis- ja privaatruumid ning kuidas saabusid uuendused uuel kodumaal elavate eestlaste kombestikku ja etnilistesse stereotüüpidesse. Missuguseid etnilisi markereid ja sümboleid (peale rahvariiete, rahvatantsuringide ja laulukooride) säilitatakse võõrsil? Kuivõrd on omavahel seotud diasporaa ja kodumaal toimuv või alluvad mõlemad hoopis üldisematele protsessidele? Missugused loome- ja säilitusmehhanismid toimivad suulise pärimuse puhul ning kui uuel kodumaal liigub eestikeelset pärimust, siis milline see on?

Eesti ja Rootsi suhteline geograafiline lähedus tekitas ka küsimuse lähisidemete ja võrgustike toimimisest totalitaarse suletud süsteemi raames. Visuaalselt olid 1990. aastate kodumaa ja läänediasporaa kodud, neis kasutatud sisustuselemendid ja tekstiilid hämmastavalt sarnased, nagu olid sarnased ka avalike ruumide kujundused. Narratiivide ja adapteerumise-säilitamise protsesside kõrval jäid tihedamalt sõelale veel kalendritavad ja rahvuslike pühade tähistamine. Esimestest intervjuudest alates selgus $\mathrm{ka}$, et diasporaa jutustused reflekteerivad kodumaal toimunut, jutustavad kodueestlastest, nende mentaliteedist ja käitumisest nähtuna diasporaa esindaja vaatepunktist, aidates nõnda rekonstrueerida pilti sotsialistlikust Eestist.

Meil on ikka kõigil igas majas Eesti lipp väljas. Tähendab, laua peal kusagil. Ja siis, kui Eestistsellel ajal tulid inimesed - Brisbane’is oli üks proua, kes tuli 
ja ütles niimoodi - näeb Eesti lippu: "Ma ei või seda vaadata. See on niisuke südamevalu. Ma ei julge, et võib-olla nad teavad, et ma olen Eesti lippu näinudja vaadanud seda."

"Kes see peab seda teadma?"

"Venelased Eestis."

Siis me saime aru, kui hirmus on see hirmutunne, kui ta on sul üdini läbi läinud.

Ütleb: "Ma ei või kohe vaadata seda lippu. Mõtle, kõik saavad teada" (Thirlmere 5).

Traumaatilised elamused ja hirm ei mõjutanud üksnes kodueestlasi, vaid kujundas lähedastega suhtlemist läbi nõukogude aja ja ilmnes ka intervjuudest. Austraalias põrkusime esimest korda kokku halvava hirmuga, millist kahju võiks tuua Eestis elavatele sugulastele meile antud intervjuu, juhul kui ajad taas muutuvad. Olin seda viimati kogenud 1980. aastate lõpul ja 1992. aasta augustis, kui küsitlesin eestivenelasi ja -ingerlasi, kes kartsid, et kriitilises olukorras võib salvestusest saada represseerimise põhjus.

\section{Kokkuvõte}

Salvestatud intervjuude põhjal on kirjutatud artikleid ja ülevaateid, aines on nüüdseks litereeritud ja selle põhjal on valmimas käsikirjad Jaan, Raudsepa talu peremees ja Austraalia lood. Visuaalsetest jäädvustustest on Andres Kuperjanovil valminud videofilm Nimetamatu ning fotonäitused Talvemaastikud. Austraaliaeestlased I ja Võõraste tähtede all. Austraaliaeestlased II, mis on nähtavad veebis (http:// www.folklore.ee/rl/pubte/ee/galerii/au01).

Läänediasporaa noorema põlvkonna, tänase pärimuse ja kombestiku jäädvustamine on jätkuvalt pakiline ülesanne. Lähemat tähelepanu vajavad passiivse eesti keele oskusega ja mitte-eestikeelsed kogukonnaliikmed, keda keele asemel seob eestluse ja diasporaaga sugulus või hoopis muud kultuurilised indikaatorid. Veel on võimalik jäädvustada müüti kodumaale tagasipöördumisest ning jäl- 
Projektid

gida uute suhete kujunemist totalitaarsest suletusest vabanenud postsotsialistliku Eesti ja diasporaa vahel. Rootsis koolihariduse saanud ja sealses keskkonnas ametit pidavate eestlaste pärimuses on olulisel kohal rootsikeelne folkloor, kohaliku kombestiku tundmine ja osadus selles, samad tendentsid kehtivad mujalgi. Omapärase saare moodustab Austraalia Thirlmere eesti küla, mille eestikeelses keskkonnas vananemine tugevdab keelelist identiteeti ja ühtekuuluvust. Jätkuvat tähelepanu vajavad aga ka diasporaa stereotüübid ja tunnused, mille kaudu iseloomustatakse ja eristatakse kanada- ja saksa-, usa-, austraalia-, rootsi- ja soome-eestlasi jt, vastavate kogukondade pärimus ja selle inskribeerimine eesti kultuurilukku. ${ }^{1}$

\section{Kommentaar}

${ }^{1}$ Diasporaa intervjuude analüüs seotud Eeesti Teadusfondi grandiga 5117.

\section{Kirjandus}

Collins, Jock 1991. Multiculturalism in Australia: The Challenges Ahead. Working Paper 7. Sidney: Sidney Institute of Technology (http://www.business.uts. edu.au/finance/research/wpapers/wp7.pdf - 10. juuli 2006).

Kõiva, Mare 2002. The Big Snowstorm I: The Spreading of Personal Experience Stories about Soviet Estonia among Estonians in Sweden. Folklore: An Electronic Journal of Folklore 21, lk 98-37 (http://www.folklore.ee/folklore/ vol21/swedes.pdf - 10. juuli 2006).

Rooth, Dan-Olof 1999. Refugee Immigrants in Sweden: Educational Investments and Labour Market Integration. Lund Economic Studies 84. Lund: Department of Economics, Lunds Universitet.

Simmul, Reet 2001. Intervjuu. Eesti Rahvaluule Arhiivi heliarhiiv, MDCD-01-01-03.

Thirlmere 5 = Intervjuu Thirlmere 5 Eesti Kirjandusmuuseumi folkloristika osakonna (KMFO) arhiivis < Austraalia, New South Wales, Thirleme eesti küla Mare Kõiva, Andres Kuperjanov - naine, 80 a (2001).

Vertovec, Steve 1999. Minority Associations, Networks and Public Policies: Re-assessing Relationships. Journal for Migration and Ethnic Studies 25: 1, lk 21-42 (http:// www.transcomm.ox.ac.uk/working\%20papers/networks.pdf-10. juuli 2006). 


\section{VÕIM \& KULTUUR 2}

\section{Koostaja ja toimetaja Mare Kõiva}

http://www.folklore.ee/pubte/eraamat/voimjakultuur2/

Koostaja ja toimetaja: Mare Kõiva

Keeletoimetaja: Mare Kalda

Inglise keele toimetaja: Tiina Kirss

Makett ja kaas: Alo Paistik

Pilditöötlus: Andres Kuperjanov

HTML: Diana Kahre

ISBN 978-9949-586-83-7 (pdf)

ISBN 978-9949-418-53-4 (trükis)

DOI: $10.7592 / \mathrm{VK} 2.2006$

Tartu 2018

Trükis ilmunud: Võim \& kultuur 2. Koostaja ja toimetaja

Mare Kõiva. Võim ja kultuur. Tartu 2006

E-raamatu valmimist toetas: EKKM14-344 Eesti keele, kultuuri ja folkloori kasutusalade laiendamine ja tutvustamine elektroonilistel infokandjatel.
(C) 2018 Eesti Kirjandusmuuseum
(C) 2018 Eesti Folkloori Instituut
(c) 2018 EKM FO rahvausundi ja meedia töörühm
(C) 2018 autorid 